\title{
Perceived medication benefits and their association with interest in using inhaled insulin in type 2 diabetes: a model of patients' cognitive framework
}

\author{
This article was published in the following Dove Press journal: \\ Patient Preference and Adherence \\ 5 June 2011 \\ Number of times this article has been viewed
}

\author{
Mark Peyrot ${ }^{1,2}$ \\ Richard R Rubin 2,3 \\ 'Department of Sociology, Loyola \\ University, MD, USA; ${ }^{2}$ Department of \\ Medicine, ${ }^{3}$ Department of Pediatrics, \\ Johns Hopkins University, Baltimore, \\ MD, USA
}

Objective: To examine predictors of patient perceived relevance of different diabetes medication benefits, and to determine how medication benefit ratings of an inhaled insulin were associated with evaluation of, and interest in that inhaled insulin.

Methods: The study was an Internet survey of a US sample $(n=1094)$ of adults with type 2 diabetes using different medication regimens. Patients were given a brief description of potential clinical benefits and administration procedures for the inhaled insulin described in this study (based on MannKind Corporation's Technosphere insulin). Measures included indicators of medication benefits, needs and relevance, benefit ratings and overall evaluation of the studied inhaled insulin relative to current medication, and interest in the study medication. Multivariate regression assessed significant $(P<0.05)$ independent associations, controlling for demographic and disease characteristics.

Results: Relevance of potential medication benefits (avoidance of hyperglycemia, hypoglycemia, weight gain, discomfort/inconvenience) was significantly associated with objective and subjective indicators of patients' needs. Most need indicators were associated only with the specific benefit to which they apply; concerns about weight and lifestyle were associated with multiple benefits. Ratings of the studied inhaled insulin for avoiding postprandial hyperglycemia and discomfort/inconvenience were associated with overall evaluation of and interest in the inhaled insulin described in this study; rating of this medication for avoiding weight gain was associated with overall evaluation ratings.

Conclusions: Relevance of different potential benefits was based on objective and subjective indicators of need. Perceived efficacy of the inhaled insulin described in this study for avoiding postprandial hyperglycemia and discomfort/inconvenience were the benefits most strongly related to the evaluation of and interest in this medication.

Keywords: type 2 diabetes, inhaled insulin, medication benefits, patient preference

\section{Introduction}

“Drugs don't work in patients who don't take them". A World Health Organization report on adherence to treatments reinforces this statement by $\mathrm{C}$ Everett Koop, former Surgeon General of the United States. ${ }^{1}$ On average, half the patients prescribed drugs for conditions common to people with diabetes (hyperglycemia, hypertension, hypercholesterolemia) stop taking them after 1 year. Thus, it is critically important to better understand several aspects of patients' diabetes medication use: adoption (filling an initial prescription), adherence (taking medication at prescribed dosage and frequency),
Correspondence: Mark Peyrot 603 Horncrest Road, Towson, MD 21204, USA

Tel +l 4109169759

Email mark.peyrot@gmail.com 
intensification (taking medication in larger doses or more frequently), and persistence (continuing treatment by refilling prescriptions).

Studies of these aspects of medication use are limited (with the exception of adherence). One study found that adoption (first-fill) rates for diabetes medication was $85 \%$, with lower rates for second-line oral agents and insulin. ${ }^{2}$ A systematic review of medication adherence and persistence found that patients with type 2 diabetes took $67 \%-85 \%$ of their oral medication doses and $62 \%-64 \%$ of their insulin doses as prescribed, and that $36 \%-93 \%$ of patients remained on treatment for 6-24 months. ${ }^{3}$ Several factors are associated with medication adherence and persistence, including patients' perception of medication benefits, side effects, and regimen complexity, as well as emotional well-being. ${ }^{4}$

Medication adoption is clearly the critical juncture in medication use; patients cannot adhere, intensify, or persist in using a medication they do not initiate. Physician recommendations appear to play an important role in patients' adoption of diabetes therapies. ${ }^{5}$ However, medication adoption may be the result of a complex interplay of physician recommendations and patient requests for medication, ${ }^{6,7}$ and patient perceptions of treatment benefits play a role in their acceptance of physician treatment recommendations. ${ }^{5}$

We propose that two processes are key to better understanding patient adoption of diabetes therapies: 1) what determines the relevance of particular medication benefits to patients, and 2) what benefits are important to patients in comparing which of the relevant medications they will choose/accept. Note that these are functions of what patients perceive and how those perceptions factor into their decisions. When making an initial decision about medication adoption, patients do not have a personal experience with any medication they have not already used themselves, but they do know what their current situation is, so their perceived needs may play a critical role in the adoption process.

Few studies explicitly examine the correlates of the importance or relevance of potential medication benefits, but some studies have implications for this issue. One study found that adoption rates for diabetes medication were higher for those with higher A1c levels, indicative of greater need for the medication. ${ }^{2}$ Another study found that among insulin-naïve patients, those with higher levels of need (poor control, more complications and diabetes distress) had a greater belief in the efficacy of insulin therapy. ${ }^{8}$ Thus, we hypothesize that subjective and objective factors indicative of need for a medication and the benefits it provides will be associated with the relevance of that medication benefit.
Several studies have examined how perceptions of specific diabetes therapy benefits are associated with overall ratings of treatment satisfaction or preference, and with adherence to or adoption of a given therapy. Use of an insulin pen rather than vial and syringe was associated with the perception that pens are better than vial and syringe for convenience/ flexibility, facilitating self-care, and clinical efficacy. ${ }^{5,9}$ Perceiving pump therapy as more clinically efficacious and contributing more to psychological well-being than multiple daily insulin injection (MDI) therapy was associated with overall preference for pump therapy. ${ }^{10}$ The perceived effects of pramlintide therapy (eg, glucose control, hypoglycemia prevention, flexible eating, appetite control) were associated with treatment satisfaction and preference. ${ }^{11}$

When looking specifically at the adoption of insulin therapy, resistance to initiating insulin therapy is common. ${ }^{8}$ Injection related problems are associated with being less willing to take more frequent insulin injections ${ }^{12}$ and more frequent omission of insulin injections. ${ }^{13}$ The use of inhaled insulin has been shown to increase patients' positive perceptions of insulin treatment ${ }^{14}$ and the availability of inhaled insulin increases patients' willingness to initiate insulin therapy. ${ }^{15}$

Based on this research we propose to examine four potential benefits of an inhaled insulin - avoidance of a) postprandial hyperglycemia, b) hypoglycemia, c) weight gain, and d) discomfort/inconvenience. Specifically, we will examine: 1) factors associated with the relevance to patients of these perceived benefits, and 2) how ratings of these perceived benefits for an inhaled insulin (compared to patients' current therapy) are associated with overall assessment of that medication, including interest in using that medication if it were available. Based on earlier research, we hypothesize that: 1) patient characteristics indicating need for a particular benefit will be most strongly associated with the relevance of the corresponding benefit - a) perceived glucose control and frequency of hyperglycemia with the importance of avoiding hyperglycemia, b) frequency and fear of hypoglycemia with the importance of avoiding hypoglycemia, c) weight and weight worry with the relevance of avoiding weight gain, and d) concern about injections with the importance of avoiding discomfort and inconvenience; 2) among potential medication benefits, clinical efficacy (avoiding hyperglycemia) and avoiding injection-related discomfort and inconvenience will be the benefits most strongly associated with higher ratings of and interest in using the inhaled insulin described in this study. This study examines these issues among adult patients with type 2 diabetes using different treatment regimens, including oral agents only, basal insulin, and MDI therapy. 


\section{Methods}

Harris Interactive developed the questionnaire in cooperation with MannKind Corporation and the authors of this paper; Synovate Consumer Opinion Panel secured the study sample and programmed and fielded the survey. The Human Subjects Research Committee at Loyola University Maryland approved the study protocol and use of the data from the project. Partial results of this study have been reported elsewhere. $^{16}$

The sampling plan was designed to generate a sample that was nationally representative of the diagnosed diabetes population, based on the 2005 National Health Interview Study according to gender, age, ethnicity, geographic region, and income. Targets for type of diabetes and diabetes treatment regimen were selected based on the 2007 US Market Study of the Roper Global Diabetes Program. Only those who had indicated that they had diabetes upon enrolling in the Synovate consumer panel were recruited for participation. Data were then weighted to diabetes population proportions.

The study population for this analysis was adult individuals who self-reported physician-diagnosed type 2 diabetes. Exclusion criteria included: using an insulin pump, taking an injected medication other than insulin, having used inhaled insulin, not taking diabetes medication, or having lung problems (asthma, reduced lung capacity, any treated lung disease, smoking history). The study population consisted of 1094 respondents, 734 who took only oral medications to control blood glucose, 228 who took basal insulin (with or without oral medications) to control blood glucose, and 132 patients who used multiple daily insulin injections (see Table 1). Patients were almost evenly divided by sex, with the majority $(78 \%)$ being white. The average age was 57 years and the average annual income was about US\$51,000. The majority of respondents had health insurance $(94 \%)$ and saw a primary care physician for their diabetes care $(82 \%)$. Patients had an average diabetes duration of 10 years. On average the population was overweight/obese $\left(\mathrm{BMI}=36 \mathrm{~m} / \mathrm{kg}^{2}\right)$ and had a moderate number of comorbidities ( 2$)$. Self-reported medication-taking for depression was moderately prevalent (19\%).

Potential study participants received an email message inviting them to participate in an Internet survey, stating that the survey would take 10 minutes to complete, offering incentives (points toward merchandise or gift cards, entry into a sweepstakes, highlights of the survey results), and providing a link to the study survey. After agreeing to participate, respondents answered questions about demographic, disease and health care characteristics, and health-related beliefs. Participants were then given a description of the study medication (see Appendix 1), after which they assessed this medication (see Measures below). The description was developed by the study sponsor (MannKind) based on studies of Technosphere inhaled insulin, indicating the potential pharmacological and clinical benefits ${ }^{17-20}$ and the then-current procedure for storage, maintenance, and use of the medication and device (subsequently simplified following results of patient use studies and product development), along with a picture of the inhaler in use at the time of the study (subsequently replaced with a smaller device).

\section{Measures}

In addition to a variety of demographic and health care characteristics, the study included measures of several indicators of objective need for medication benefits, including frequency of high blood glucose (for avoiding hyperglycemia), frequency of low blood sugar (for avoiding hypoglycemia), and weight/BMI (for avoiding weight gain). The study also included subjective measures (described below) of: healthrelated beliefs; relevance to the patient of potential benefits of the studied inhaled insulin; assessments of the study medication compared to the patient's current treatment; and interest in this medication (see Appendix 2).

\section{Health-related beliefs}

The questionnaire incorporated questions regarding healthrelated beliefs; there were six response options ranging from agree completely to disagree completely (scored 100 to 0 , with reverse scoring where appropriate). Items were selected to represent several dimensions of subjective need for potential medication benefits. Reliability analyses were conducted to identify items within each measure that lowered inter-item agreement; these items were deleted. The analysis resulted in four measures, with each multi-item measure calculated as the mean of component items: negative perceptions of injections ( 5 items, alpha $=0.74)$, treatment restrictions on lifestyle ( 2 items, alpha $=0.71$ ), weight worry ( 4 items, alpha $=0.74$ ), fear of hypoglycemia ( 1 item). Another measure representing perceived lack of diabetes control was calculated as the mean of three items based on 10-point response scales scored 100 to 0 , with higher scores indicating worse control $($ alpha $=0.71)$.

\section{Relevance of medication benefits}

There were four single-item measures, each indicating how relevant one of the following benefits was to the patient: avoiding high blood sugar after meals, avoiding low blood sugar, avoiding weight gain, avoiding discomfort and inconvenience. 
Table I Sample profile by medication group

\begin{tabular}{|c|c|c|c|c|}
\hline Measures & $\begin{array}{l}\text { Oral only } \\
(n=734)\end{array}$ & $\begin{array}{l}\text { Basal insulin } \\
(n=228)\end{array}$ & $\begin{array}{l}\text { MDI } \\
(n=132)\end{array}$ & $\begin{array}{l}\text { Total } \\
(\mathrm{n}=1094)\end{array}$ \\
\hline \multicolumn{5}{|l|}{ Demographics } \\
\hline Age (years) & $57.0 \pm 10.7$ & $58.5 \pm 9.3$ & $57.7 \pm 11.4$ & $57.4 \pm 10.5$ \\
\hline Female & $47.1(346)$ & $57.0(130)$ & $59.1(78)$ & $50.6(554)$ \\
\hline \multicolumn{5}{|l|}{ Race/ethnicity } \\
\hline White & $75.6(555)$ & $79.4(18 I)$ & $85.6(113)$ & $77.6(849)$ \\
\hline Black & II.7 (86) & $10.5(24)$ & $9.8(13)$ & II.2 (I23) \\
\hline Hispanic & $9.3(68)$ & $7.0(16)$ & $2.3(3)$ & $8.0(87)$ \\
\hline Other race & $3.4(25)$ & $3.1(7)$ & $2.3(3)$ & $3.2(35)$ \\
\hline Education* & $5.2 \pm 1.7$ & $5.0 \pm 1.6$ & $4.8 \pm 1.7$ & $5.1 \pm 1.6$ \\
\hline Income (thousands of $\$)^{* *}$ & $53.4 \pm 36.0$ & $46.5 \pm 33.1$ & $46.0 \pm 38.2$ & $51.1 \pm 35.8$ \\
\hline \multicolumn{5}{|l|}{ Health care } \\
\hline \multicolumn{5}{|l|}{ Health care provider*** } \\
\hline $\mathrm{PCP}$ & $87.3(64 I)$ & $78.9(180)$ & $60.9(8 I)$ & $82.4(902)$ \\
\hline Endocrinologist & $9.9(73)$ & $19.7(45)$ & $34.6(46)$ & $15.0(164)$ \\
\hline Other HCP & $2.7(20)$ & $1.3(3)$ & $4.5(6)$ & $2.6(29)$ \\
\hline \multicolumn{5}{|l|}{ Health insurance* } \\
\hline No insurance & 7.1 (52) & $4.8(\mathrm{II})$ & $3.8(5)$ & $6.2(68)$ \\
\hline Private insurance & $71.4(525)$ & $64.8(147)$ & $66.2(88)$ & $69.4(760)$ \\
\hline Medicare insurance & $8.8(65)$ & I4.| (32) & $12.0(16)$ & $10.3(1 \mid 3)$ \\
\hline Military insurance & $7.1(52)$ & $7.9(18)$ & $6.8(9)$ & $7.2(79)$ \\
\hline Medicaid insurance & $5.6(4 I)$ & $8.4(19)$ & II.3 (I5) & $6.8(75)$ \\
\hline \multicolumn{5}{|l|}{ Disease } \\
\hline Pen use $\mathrm{e}^{* * *}$ & $0(0)$ & $23.2(53)$ & $40.2(53)$ & $9.7(106)$ \\
\hline Duration of DM*** & $8.1 \pm 7.1$ & $13.4 \pm 8.6$ & $15.6 \pm 10.0$ & $10.1 \pm 8.3$ \\
\hline \multicolumn{5}{|l|}{ Hypoglycemia**** } \\
\hline NA & $10.9(80)$ & $4.8(\mathrm{II})$ & I.5 (2) & $8.5(93)$ \\
\hline None & $36.6(269)$ & $18.9(43)$ & I5.2(20) & $30.3(332)$ \\
\hline Occasionally & $46.7(343)$ & $67.0(152)$ & $69.7(92)$ & $53.7(587)$ \\
\hline Frequently & $5.9(43)$ & $9.3(21)$ & $13.6(18)$ & $7.5(82)$ \\
\hline \multicolumn{5}{|l|}{ Hyperglycemia*** } \\
\hline NA & $10.9(80)$ & $4.8(\mathrm{II})$ & $1.5(2)$ & $8.5(93)$ \\
\hline None & $19.2(14 \mid)$ & $12.7(29)$ & $6.8(9)$ & 16.4 (I79) \\
\hline Occasionally & $50.7(372)$ & $48.7(111)$ & $43.2(57)$ & $49.4(540)$ \\
\hline Frequently & $19.2(141)$ & $33.8(77)$ & $48.5(64)$ & $25.8(282)$ \\
\hline BMI*** & $35.2 \pm 8.0$ & $37.6 \pm 9.6$ & $37.1 \pm 9.5$ & $35.9 \pm 8.6$ \\
\hline $\mathrm{Nr}$ of comorbidities $* * *$ & $1.9 \pm 1.2$ & $2.2 \pm 1.3$ & $2.6 \pm 1.6$ & $2.1 \pm 1.3$ \\
\hline Depression (taking medication)*** & $15.6(115)$ & $24.2(55)$ & $25.6(34)$ & I8.6 (204) \\
\hline \multicolumn{5}{|l|}{ Beliefs } \\
\hline Poor DM control*** & $30.8 \pm 18.1$ & $39.5 \pm 17.7$ & $40.2 \pm 15.8$ & $33.7 \pm 18.2$ \\
\hline Hypoglycemia fear*** & $38.2 \pm 29.5$ & $48.3 \pm 28.8$ & $49.8 \pm 31.9$ & $41.7 \pm 30.1$ \\
\hline Weight concern*** & $50.9 \pm 22.5$ & $60.1 \pm 24.5$ & $65.5 \pm 24.4$ & $54.6 \pm 24.0$ \\
\hline Negative injections $* * *$ & $50.8 \pm 22.1$ & $28.6 \pm 20.3$ & $23.7 \pm 19.6$ & $42.9 \pm 24.3$ \\
\hline Treatment restrictions*** & $32.8 \pm 26.4$ & $42.9 \pm 27.2$ & $41.9 \pm 29.5$ & $36.0 \pm 27.3$ \\
\hline \multicolumn{5}{|l|}{ Study medication benefit relevance } \\
\hline Avoid high BG*** & $68.1 \pm 29.2$ & $75.8 \pm 24.3$ & $77.3 \pm 26.1$ & $70.8 \pm 28.1$ \\
\hline Avoid low BG**** & $61.2 \pm 31.5$ & $69.6 \pm 27.7$ & $68.5 \pm 30.9$ & $63.8 \pm 30.8$ \\
\hline Avoid weight gain** & $70.1 \pm 30.9$ & $74.8 \pm 28.0$ & $79.3 \pm 27.6$ & $72.2 \pm 30.1$ \\
\hline Avoid discomfort and inconvenience & $65.6 \pm 32.3$ & $66.2 \pm 29.3$ & $65.0 \pm 33.0$ & $65.6 \pm 31.3$ \\
\hline \multicolumn{5}{|l|}{ Study medication benefit rating } \\
\hline Avoid high BG*** & $15.8 \pm 21.1^{\mathrm{a}}$ & $22.7 \pm 19.6^{\mathrm{a}}$ & $22.2 \pm 20.3^{\mathrm{a}}$ & $18.0 \pm 20.9^{\mathrm{a}}$ \\
\hline Avoid low BG*** & $13.6 \pm 20.9^{a}$ & $21.0 \pm 20.3^{\mathrm{a}}$ & $19.8 \pm 21.4^{\mathrm{a}}$ & $15.9 \pm 21.0^{\mathrm{a}}$ \\
\hline Avoid weight gain $* * *$ & $16.8 \pm 22.5^{\mathrm{a}}$ & $25.7 \pm 20.5^{\mathrm{a}}$ & $23.9 \pm 21.4^{\mathrm{a}}$ & $19.5 \pm 22.2^{\mathrm{a}}$ \\
\hline Avoid discomfort and inconvenience*** & $17.8 \pm 23.7^{\mathrm{a}}$ & $25.0 \pm 22.2^{\mathrm{a}}$ & $24.2 \pm 22.4^{\mathrm{a}}$ & $20.1 \pm 23.4^{\mathrm{a}}$ \\
\hline \multicolumn{5}{|l|}{ Study medication assessment } \\
\hline Comparison to current medication $* * *$ & $15.3 \pm 25.2^{\mathrm{a}}$ & $25.7 \pm 21.7^{\mathrm{a}}$ & $26.8 \pm 20.9^{\mathrm{a}}$ & $18.9 \pm 24.6^{\mathrm{a}}$ \\
\hline
\end{tabular}


Table I (Continued)

\begin{tabular}{|c|c|c|c|c|}
\hline Measures & $\begin{array}{l}\text { Oral only } \\
(n=734)\end{array}$ & $\begin{array}{l}\text { Basal insulin } \\
(n=228)\end{array}$ & $\begin{array}{l}\text { MDI } \\
(n=132)\end{array}$ & $\begin{array}{l}\text { Total } \\
(n=1094)\end{array}$ \\
\hline Interest in using & $67.2 \pm 27.6$ & $69.9 \pm 28.7$ & $73.2 \pm 27.9$ & $68.5 \pm 27.9$ \\
\hline Impact on insulin initiation & $28.7 \pm 23.1$ & NA & NA & $28.7 \pm 23.1$ \\
\hline
\end{tabular}

Notes: Education: I = less than high school, 2 = completed some high school, 3 = high school graduate or equivalent, $4=$ trade school, $5=$ completed some college, $6=$ college graduate, 7 = completed some graduate work, $8=$ completed graduate degree. Cell entries are mean \pm standard deviation or $\%(n)$. ${ }^{\text {Mean }}$ is significantly $(P<0.00 \mathrm{I})$ different from rating of no difference from current medication $(=0)$. $* P<0.05$ for medication group differences; $* * P<0.0$ I for medication group differences; $* * * P<0.00$ I for medication group differences.

Abbreviations: BG, blood glucose; BMI, body mass index; DM, diabetes mellitus; HCP, health care provider; MDI, multiple daily insulin injection; NA, not ascertained; $\mathrm{PCP}$, primary care provider.

There were five response options ranging from "extremely relevant" $(=100)$ to "not at all relevant" $(=0)$.

\section{Study medication assessment}

There were seven single-item measures. Four measures compared the inhaled insulin described in this study to the patient's current treatment, one item for each of four potential benefits: avoiding high blood sugar after meals, avoiding low blood sugar, avoiding weight gain, avoiding discomfort and inconvenience. There were five response options ranging from the study medication being "much better" $(=50)$ to "much worse" $(=-50)$ with a midpoint of "about the same" $(=0)$. There was also an item that asked for an overall evaluation comparing the studied inhaled insulin to the patient's current treatment, with identical response options and scoring. Interest in using the study medication, if it were to become available, was rated using a 5-point scale from "extremely interested" (=100) to "not at all interested" $(=0)$. Impact of the availability of the study medication on willingness to initiate insulin use (asked only among those not currently using insulin) was assessed with a 5-point response scale ranging from "much more willing" $(=50)$ to "much less willing" (=-50), with a midpoint of "neither more or less willing" $(=0)$.

\section{Statistical analysis}

All study measures were compared among the three medication groups: oral medication only, basal insulin (with or without oral medication), and multiple daily injections (MDI). Chi-square was used for categorical variables, and ANOVA was used for continuous variables.

Analysis of the correlates of benefit relevance, interest in using the inhaled insulin described in this study, and overall assessment comparing the medication used in this study with current treatment used ordinary least squares multiple regression. All correlates were forced into the model to control for potential confounding and assess the independent contribution of each factor to the explanatory models.

\section{Results}

Health-related beliefs were neither extremely positive nor extremely negative; on a scale of 0 to 100 , means ranged between 23 and 66 (see Table 1). All four study medication benefits were rated as relevant with means ranging from 61 to 80 . The studied inhaled insulin was rated significantly better than the patients' current treatments for all benefits in all groups (means between 13 and 26 where 0 represents no difference and the range is 50 to -50 ). Using the same scale, the study medication was rated better overall than current treatment by all medication groups (means between 15 and 27), and all medication groups indicated an interest in using the studied inhaled insulin (means between 67 and 74 on a scale of 0 to 100). Respondents taking only oral diabetes medication indicated that the availability of the study medication would substantially increase their willingness to initiate insulin treatment (mean of 29 where 0 represents no difference and the range is 50 to -50 ).

Table 2 presents the correlates of benefit relevance (for avoiding: high blood sugar after meals, low blood sugar, weight gain, discomfort/convenience), the overall assessment of the inhaled insulin described in this study compared to current treatment, and interest in using this drug. Significant correlates of benefit relevance included a number of demographic, disease, and health care provision characteristics. Each benefit relevance measure was significantly associated with one or more demographic and disease characteristics. Although medication groups differed on three of four relevance measures, these differences disappeared when all other factors were controlled.

All factors indicating need for a particular benefit were associated with the relevance of that benefit; avoiding postprandial hyperglycemia was associated with more frequent hyperglycemia and worse perceived diabetes control; avoiding hypoglycemia was associated with more frequent hypoglycemia and fear of hypoglycemia; avoiding weight gain was associated with higher BMI and more weight worry; avoiding discomfort/inconvenience was associated 
Table 2 Correlates of benefit relevance ratings, interest in study medication, and comparison of study medication to current medication ${ }^{\mathrm{a}}$

\begin{tabular}{|c|c|c|c|c|c|c|}
\hline Correlate & $\begin{array}{l}\text { Relevance } \\
\text { of avoiding } \\
\text { high BG }\end{array}$ & $\begin{array}{l}\text { Relevance } \\
\text { of avoiding } \\
\text { low BG }\end{array}$ & $\begin{array}{l}\text { Relevance } \\
\text { of avoiding } \\
\text { weight gain }\end{array}$ & $\begin{array}{l}\text { Relevance of } \\
\text { avoiding discomfort } \\
\text { and inconvenience }\end{array}$ & $\begin{array}{l}\text { Compare study } \\
\text { medication to } \\
\text { current medication }\end{array}$ & $\begin{array}{l}\text { Interest } \\
\text { in study } \\
\text { medication }\end{array}$ \\
\hline \multicolumn{7}{|l|}{ Demographics } \\
\hline Age (years) & -0.022 & 0.023 & -0.039 & 0.004 & 0.051 & 0.028 \\
\hline Female & $0.078^{*}$ & $0.094^{* *}$ & $0.099 * * *$ & $0.097 * *$ & 0.013 & -0.029 \\
\hline Black $^{\mathrm{b}}$ & 0.048 & $0.085 * *$ & 0.044 & $0.079 *$ & 0.043 & -0.023 \\
\hline Hispanic ${ }^{b}$ & 0.046 & $0.070^{*}$ & 0.042 & 0.054 & $0.090 * * *$ & 0.047 \\
\hline Other race ${ }^{\mathrm{b}}$ & 0.000 & 0.006 & -0.012 & 0.003 & 0.045 & 0.020 \\
\hline Education & 0.045 & 0.016 & $0.067^{*}$ & 0.050 & $-0.060 *$ & 0.011 \\
\hline Income & 0.028 & 0.028 & 0.046 & -0.012 & $0.060^{*}$ & $0.072^{*}$ \\
\hline \multicolumn{7}{|l|}{ Health care } \\
\hline Endocrinologist ${ }^{\mathrm{e}}$ & -0.010 & -0.024 & -0.029 & -0.037 & -0.016 & -0.051 \\
\hline Other $\mathrm{HCP}$ & $-0.070 *$ & -0.020 & $-0.057^{*}$ & -0.039 & -0.022 & -0.014 \\
\hline No insurance ${ }^{f}$ & -0.004 & -0.008 & 0.024 & -0.001 & 0.046 & 0.040 \\
\hline Medicare insurance ${ }^{f}$ & -0.006 & -0.021 & -0.032 & -0.045 & 0.010 & -0.059 \\
\hline Military insurance ${ }^{f}$ & -0.023 & -0.041 & 0.010 & 0.022 & 0.008 & -0.046 \\
\hline Medicaid insurance ${ }^{f}$ & 0.041 & 0.022 & 0.008 & 0.029 & 0.039 & 0.039 \\
\hline \multicolumn{7}{|l|}{ Disease } \\
\hline Basal insulinc & 0.026 & 0.034 & -0.006 & 0.029 & 0.023 & -0.034 \\
\hline $\mathrm{MDI}^{\mathrm{c}}$ & 0.010 & 0.000 & 0.011 & 0.009 & 0.028 & 0.016 \\
\hline Pen use & 0.061 & 0.021 & 0.035 & 0.055 & 0.039 & 0.019 \\
\hline Duration of DM & -0.032 & -0.028 & 0.027 & -0.041 & 0.008 & 0.014 \\
\hline BMI (log) & -0.052 & -0.058 & $0.073 *$ & -0.004 & 0.018 & -0.002 \\
\hline $\mathrm{Nr}$ of comorbidities & 0.028 & 0.004 & 0.054 & $0.093 * *$ & 0.032 & 0.048 \\
\hline Depression & 0.031 & -0.001 & 0.042 & -0.043 & -0.013 & 0.028 \\
\hline $\begin{array}{l}\text { Hypoglycemia } \\
\text { (occasionally) }^{d}\end{array}$ & 0.001 & $0.154^{* * *}$ & 0.026 & 0.004 & 0.014 & -0.056 \\
\hline $\begin{array}{l}\text { Hypoglycemia } \\
\text { (frequently) }^{d}\end{array}$ & -0.018 & $0.150 * * *$ & 0.034 & -0.010 & -0.030 & -0.040 \\
\hline $\begin{array}{l}\text { Hyperglycemia } \\
\text { (occasionally) }^{d}\end{array}$ & $0.149 * * *$ & -0.055 & 0.000 & -0.016 & $0.075^{*}$ & 0.045 \\
\hline $\begin{array}{l}\text { Hyperglycemia } \\
\text { (frequently) }^{d}\end{array}$ & $0.205^{* * *}$ & -0.012 & 0.056 & 0.057 & $0.117 * *$ & 0.038 \\
\hline \multicolumn{7}{|l|}{ Beliefs } \\
\hline Poor DM control & $0.120 * * *$ & 0.053 & 0.009 & 0.038 & $0.075^{*}$ & 0.050 \\
\hline Hypoglycemia fear & 0.001 & $0.217^{* * *}$ & -0.029 & 0.035 & -0.009 & -0.013 \\
\hline Weight concern & $0.128^{* * *}$ & $0.073 *$ & $0.344 * * *$ & 0.064 & 0.024 & $0.068^{*}$ \\
\hline Negative injections & -0.012 & -0.036 & 0.001 & $0.174 * * *$ & -0.011 & 0.026 \\
\hline Treatment restrictions & $0.095 * *$ & 0.055 & -0.011 & $0.087^{*}$ & $0.143^{* * *}$ & 0.040 \\
\hline \multicolumn{7}{|l|}{ Benefits } \\
\hline Avoid high BG & & & & & $0.196 * * *$ & $0.188 * * *$ \\
\hline Avoid low BG & & & & & 0.009 & 0.046 \\
\hline Avoid weight gain & & & & & $0.127^{* *}$ & 0.074 \\
\hline $\begin{array}{l}\text { Avoid discomfort } \\
\text { and inconvenience }\end{array}$ & & & & & $0.174 * * *$ & $0.224^{* * * *}$ \\
\hline R-squared & 0.165 & 0.166 & $0.24 I$ & 0.125 & 0.381 & 0.301 \\
\hline
\end{tabular}

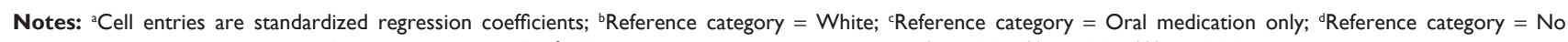

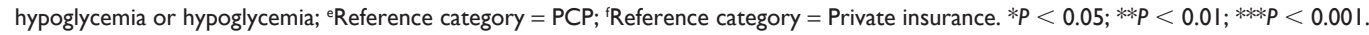

Abbreviations: BG, blood glucose; BMI, body mass index; DM, diabetes mellitus; HCP, health care provider; MDI, multiple daily insulin injection; NA, not ascertained; PCP, primary care provider.

with more perceived treatment restrictions and more negative perceptions of injection. Two subjective indicators of need were associated with relevance of a benefit other than hypothesized - treatment restrictions were associated with relevance of avoiding hyperglycemia, and weight worry was associated with relevance of avoiding hyperglycemia and hypoglycemia.

Table 2 also presents the associations with overall evaluation of and interest in the studied inhaled insulin. Several demographic and health care factors were significantly 
associated with one or both of these overall assessment measures. Other than perceived medication benefits, the factors most strongly associated with overall assessment were indicators of need: those with more frequent hyperglycemia, more poorly controlled diabetes, and more perceived treatment restrictions rated the inhaled insulin described in this study more positively compared to their current treatment; those with more weight worry were more interested in the study medication.

Although all medication benefits had significant relationships to both overall assessment measures prior to their entry into the model, when entered together to assess independent associations, some became nonsignificant. Only avoiding high blood sugar after meals and avoiding discomfort and inconvenience remained significantly associated with both interest in and overall evaluation of the study medication; avoiding weight gain remained significantly associated with overall evaluation of the study medication.

\section{Discussion}

This study's findings indicate that a number of demographic characteristics, health care provision factors, disease characteristics, and health-related beliefs are significantly associated with the relevance of several potential benefits and overall assessment of the inhaled insulin examined in this study. This study yields several findings regarding correlates of diabetes medication benefit relevance:

First, the relevance of potential medication benefits is independently related to each of the categories of factors examined in the study - patient demographic characteristics, disease traits and experiences, and health-related beliefs.

Second, the relevance of several potential benefits of diabetes medications tends to vary consistently with a number of patient characteristics. That is, any given factor (eg, female sex) tends to be associated in the same direction, albeit to a greater or lesser degree, with the relevance of each benefit examined.

Third, the strongest correlates of the relevance of a benefit are the objective and subjective indicators of need for that benefit. Moreover, few of the need factors were associated with the salience of a benefit other than that for which it indicates need. Thus, these associations exhibit both sensitivity and specificity. Weight worry and treatment-related restrictions of lifestyle were the only need factors associated with other benefit relevance measures; this is consistent with research suggesting that these factors may be indicators of global health-related distress..$^{9,21,22}$
The study also yields several findings regarding correlates of overall assessment of the study medication compared to patients' current treatment. First, the findings generally parallel those reported above for benefit relevance; the overall assessment measures are independently related to every category of factor examined in the study, and they tend to vary consistently with patient characteristics.

Second, both objective and subjective factors indicative of need for medication benefits are associated with overall assessment of the inhaled insulin described in this study, even when ratings of the benefits of that medication are controlled. This study replicates earlier research suggesting that weight worry ${ }^{21}$ and negative attitudes toward insulin ${ }^{22}$ may be important factors in a variety of patient decisions and actions related to diabetes medication, and is consistent with findings in this study regarding generalized associations of these factors with benefit relevance.

Third, among the benefit ratings, only avoiding high blood sugar after meals and discomfort/inconvenience have consistently strong independent relationships with overall assessment of the study medication; avoiding weight gain has a weaker and less consistent, albeit significant, independent relationship.

Taken together, these two sets of findings help identify which medication benefits are most important to patients. Results suggest that patients will evaluate diabetes medications primarily in terms of their ability to control postprandial hyperglycemia and reduce discomfort and inconvenience. These results replicate and extend those of a recent study demonstrating that perceived control of postprandial glucose levels was the strongest predictor of overall assessment of another diabetes medication. ${ }^{11}$ That study was not able to examine the impact of comfort/convenience on medication assessment, but the current study indicates that this factor may have an impact of roughly the same size as efficacy in controlling postprandial hyperglycemia.

In earlier studies we found that the impact of convenience on facilitating better self-care was a major factor in patients' and physicians' decisions about initiation of diabetes treatment. ${ }^{5,7}$ While the current study did not distinguish between convenience for its own sake and convenience that makes better self-care possible, it is important to recognize that these factors are closely related. Moreover, if patients do not agree to initiate and sustain use of a medication, that medication will not be used no matter how clinically efficacious it is. Thus, convenience should not be dismissed as unimportant from a clinical or payer perspective. 
Our study did not identify an association between overall assessment of the study medication and its relative efficacy in avoiding hypoglycemia. Does this mean that hypoglycemia does not play a role in patients' diabetes medication decisions? We think not, because studies have shown concerns about hypoglycemia to be a major factor in patients' medication related decisions. ${ }^{23,24}$ It may be that the medication description used in this study did not convince patients that the study medication would be effective in avoiding hypoglycemia; indeed the rating for this benefit (compared to current treatment) was lower than other potential benefits. It remains to be seen whether beliefs about hypoglycemia are resistant to change, or whether patients require either a) a more effective explanation of the ways that a medication might help avoid hypoglycemia or b) actual experience of changes in the level of hypoglycemia.

Respondents not currently taking insulin indicated that the availability of the study inhaled insulin would reduce the barriers to initiation of insulin therapy. This finding should be viewed with caution as it may involve a discrepancy between word and deed. However, a randomized controlled trial to examine the impact of availability of an inhaled insulin showed an increase in the initiation of insulin therapy. ${ }^{25}$ Yet it remains to be determined whether the availability of the study inhaled insulin would have an effect on initiation of insulin therapy in a real-world setting. Answering this question will depend on whether an inhaled insulin is brought to market, a possibility that is not certain at this point in time.

\section{Study strengths and limitations}

The strengths of this study include the large and diverse sample, and the extensive collection of measures that could be examined and controlled. One weakness of the study is the lack of variation in the description of medication benefits. ${ }^{26}$ Thus, it was not possible to test trade-offs among these benefits, nor whether these same benefits would influence preference for other methods of insulin administration or other insulin formulations. However, the study did assess the benefits thought to be realistic for a given medication (Technosphere insulin) as compared to other medications that were actually being used or available for use by patients. ${ }^{18}$ It is not possible to know how a given medication might be described by any actual clinician in discussing initiation of that medication with an individual patient, so this is an inherent limitation of any study that does not either specify or measure the clinician's actions. Physicians' explanations and recommendations may influence or override patients' initial preferences for a particular medication, and thus are a crucial contextual factor in the study of patient preferences. Thus, it is important to understand how physicians (and other professionals involved in decisions about diabetes medications) perceive inhaled insulin and how they would present this therapeutic option to patients. $^{27}$

This study not only assessed the impact of perceived clinical efficacy (hyperglycemia avoidance) on medication preference, it also assessed the impact of the most clinically significant common side effects of insulin therapy (hypoglycemia, weight gain). One major nonclinical consideration not examined in this study is the impact of cost on medication preference. Cost can play a major role in medication preference, especially when the effective cost to the patient (taking into account the patient's health care coverage) varies between medications. However, a consideration of the impact of cost under different insurance coverages or health care policies was beyond the scope of the present study.

\section{Clinical implications}

Patients may choose their diabetes medications based on the benefits identified here - avoiding high blood glucose and discomfort/inconvenience, so it is important not to underestimate the demands made by the treatment regimen; uncomfortable and inconvenient treatments may be rejected by patients even if they are effective. Respondents not taking insulin in this study indicated that they would be more willing to initiate insulin therapy if a more convenient insulin delivery system that provided good glucose control were available. Additionally, patients may have better medication adherence and maintenance and be more willing to intensify treatment with such a system (although we did not examine these possibilities in the current study). Finally, this study suggests that the benefits perceived to characterize the study medication may also improve patient outcomes if they could be achieved by other insulin formulations or administration methods.

\section{Research implications}

We need additional research to examine the benefit profiles of different medications and the trade-offs patients make in choosing medications. The ultimate goal of such research should be to determine whether these benefit profiles affect real-life decisions and actions, such as medication initiation, adherence, intensification, and persistence. 


\section{Acknowledgment}

MannKind Corporation made the data available to the authors.

\section{Disclosure}

This work was supported by an unrestricted grant from MannKind Corporation. MP and RRR have received consulting fees and research funding from MannKind Corporation.

\section{References}

1. World Health Organization. Adherence to long-term therapies. Geneva, Switzerland: WHO; 2003.

2. Shah NR, Hirsch AG, Zacker C, et al. Factors associated with first-fill adherence rates for diabetic medications: a cohort study. J Gen Intern Med. 2009;24(2):233-237.

3. Cramer J. A systematic review of adherence with medications for diabetes. Diabetes Care. 2004;27(9):1218-1224.

4. Rubin RR. Adherence to pharmacologic therapy in patients with type 2 diabetes mellitus. Am J Med. 2005;118(Suppl 5A):27S-35S.

5. Rubin RR, Peyrot M. Factors affecting use of insulin pens by patients with type 2 diabetes. Diabetes Care. 2008;31(3): 430-432.

6. Kravitz RL, Epstein RM, Feldman MD, et al. Influence of patients' requests for direct-to-consumer advertised antidepressants: a randomized controlled trial. JAMA. 2005;293(16):1995-2002.

7. Peyrot M, Rubin RR. Physician perception and recommendation of insulin pens for patients with type 2 diabetes. Curr Med Res Opin. 2008;24(8):2413-2422.

8. Peyrot M, Rubin RR, Lauritzen T, et al. Resistance to insulin therapy among patients and providers: results of the cross-national Diabetes Attitudes, Wishes, and Needs study (DAWN). Diabetes Care. 2005;28(11):2673-2679.

9. Rubin RR, Peyrot M. Quality of life, treatment satisfaction, and treatment preference associated with use of a pen device delivering a premixed 70/30 insulin aspart suspension (aspart protamine suspension/ soluble aspart) versus alternative treatment strategies. Diabetes Care. 2004;27(10):2495-2497.

10. Peyrot M, Rubin RR. Validity and reliability of an instrument for assessing health-related quality of life and treatment preference: the Insulin Delivery System Rating Questionnaire. Diabetes Care. 2005;28(1):53-58.

11. Peyrot M, Rubin RR. How does treatment satisfaction work?: modeling determinants of treatment satisfaction and preference. Diabetes Care. 2009;32(8):1411-1417.

12. Rubin RR, Peyrot M, Kruger D, Travis L. Barriers to insulin injection therapy: patient and health care provider perspectives. Diabetes Educator. 2009;35(6):1014-1022.
13. Peyrot M, Rubin RR, Kruger D, Travis L. Correlates of insulin injection omission. Diabetes Care. 2010;33(2):243-248.

14. Peyrot M, Rubin RR. Effect of Technosphere inhaled insulin on quality of life and treatment satisfaction. Diabetes Technol Therapeutics. 2010; 12(1):49-55.

15. Freemantle N, Blonde L, Duhot D, et al. Availability of inhaled insulin promotes greater perceived acceptance of insulin therapy in patients with type 2 diabetes. Diabetes Care. 2005;28(2):427-428.

16. Peyrot M, Rubin RR. Perceived medication benefits and their association with interest in using inhaled insulin in type 2 diabetes: a model of patients' cognitive framework. Diabetes. 2010;59(Suppl 1):A52.

17. Rosenstock J, Bergenstal R, DeFronzo RA, et al. Efficacy and safety of Technosphere inhaled insulin compared with Technosphere powder placebo in insulin-naïve type 2 diabetes suboptimally controlled with oral agents. Diabetes Care. 2008;31(11):2177-2182.

18. Rosenstock J, Lorber DL, Gnuidi L, et al. Prandial inhaled insulin plus basal insulin glargine versus twice daily biaspart insulin for type 2 diabetes: a multicentre randomized trial. Lancet. 2010; 375(9733):2244-2253.

19. Amin V, Boss AH, Petrucci RE, et al. Pulmonary functions (over 2 years) in diabetic subjects treated with $\mathrm{Afresa}^{\mathrm{TM}}$ or usual antidiabetic treatment. Diabetes. 2009;58(Suppl 1):A153.

20. Heinemann L, Heise T. Current status of the development of inhaled insulin. Br J Diabetes Vascular Dis. 2004;4(5):295-301.

21. Peyrot M, Skovlund S, Landgraf R. Epidemiology and correlates of weight worry in the multi-national Diabetes Attitudes, Wishes and Needs (DAWN) Study. Curr Med Res Opin. 2009;25(8):1985-1993.

22. Makine C, Karsidag C, Kadioglu P, et al. Symptoms of depression and diabetes-specific emotional distress are associated with a negative appraisal of insulin therapy in insulin-naïve patients with type 2 diabetes mellitus. A study from the European Depression in Diabetes [EDID] Research Consortium. Diabet Med. 2009;26(1):28-33.

23. Peyrot M, McMurry JF, Hedges R. Living with diabetes: the role of personal and professional knowledge in symptom and regimen management. In: Roth J, Conrad P, editors. Research in the Sociology of Health Care, Vol 6. Greenwich, CT: JAI Press; 1987:107-146.

24. Cox DJ, Irvine A, Gonder-Frederick L, et al. Fear of hypoglycemia: quantification, validation, and utilization. Diabetes Care. 1987;10(5):617-621.

25. Del Prato S, Blonde L, Martinez L, et al. The effect of the availability of inhaled insulin on glycaemic control in patients with type 2 diabetes failing on oral therapy: the evaluation of Exubera as a therapeutic option on insulin initiation and improvement in glycaemic control in clinical practice. Diabet Med. 2008;25(6):662-670.

26. Guimarães C, Marra CA, Gill S, et al. A discrete choice experiment evaluation of patients' preferences for different risk, benefit, and delivery attributes of insulin therapy for diabetes management. Patient Prefer Adherence. 2010;4:433-440.

27. Rubin RR, Peyrot M. Factors associated with physician perceptions of and willingness to recommend inhaled insulin. Current Med Res Opin. 2011;27(2):285-294. 


\section{Appendix I \\ Survey description of study inhaled insulin}

Brand $\mathrm{X}$ is a new type of insulin designed for treatment of type 1 or type 2 diabetes in adults. For type 1 diabetes, Brand X should be used in combination with a long-acting (basal) insulin. For type 2 diabetes, Brand X can be used alone instead of rapid-acting or regular human insulin, or combination with either oral medications or long acting insulins. Use of Brand $\mathrm{X}$ is not recommended for patients who have asthma, poorly controlled lung disease, or who smoke. Brand $\mathrm{X}$ has a unique method of action that lets it work faster than current insulins, to more quickly bring your blood sugar back into the normal range after your meal. Because of its speed of action, Brand X has also shown: A greatly reduced incidence of severe hypoglycemia (low blood sugar) compared to currently available mealtime insulins; no weight gain was observed among patients in long-term clinical trials using Brand X insulin.

Brand $\mathrm{X}$ comes in a dry powder form of insulin that is inhaled at the start of a meal, using a palm-sized inhaler. The dry powder turns into a liquid when it enters the lungs for easy absorption into the blood stream. It comes in small cartridges containing a single premeasured dose, which are inserted in the inhaler before use. Each individual cartridge requires two inhalations. The insulin has a total shelf life of 18 months when refrigerated. The insulin is stable at room temperature for 3 months. The mouthpiece needs to be cleaned every 2 weeks.

\section{Appendix 2}

\section{Question wording for subjective survey} measures

Scoring of responses for belief items $(100=$ Agree completely, $80=$ Agree somewhat, $60=$ Agree slightly, $40=$ Disagree slightly, $20=$ Disagree somewhat, $0=$ Disagree completely).

\section{Negative perceptions of injections}

- If I have to inject myself to give insulin, it is/would be no big deal (Reverse Scored)

- I am not/would not be comfortable with injecting myself to give myself insulin

- Having to take shots is the biggest drawback to taking insulin

- I am/would be ok with one injection of insulin a day but I would never consider taking it more often

- Insulin injections are/would be very painful

\section{Treatment restrictions on lifestyle}

- I get so frustrated by my diabetes and the limits it puts on my lifestyle

- Taking good care of my diabetes limits my daily flexibility

\section{Weight worry}

- My doctor considers weight to be a major problem in keeping me from better managing my diabetes

- I am very worried about gaining weight

- Insulin causes weight gain

- Diabetes has caused my weight to increase significantly

\section{Fear of hypoglycemia}

- I worry a lot about having blood sugar lows

\section{Poor diabetes control}

- How severe do you think your diabetes is? $(100=$ Less severe than others with diabetes.....0 = More severe than others with diabetes)

- How well are you able to control your diabetes? $(100=$ Able to control extremely well $\ldots . .0=$ Not at all able to control)

- How well do you follow-through on the treatment plan that your doctor has prescribed for your diabetes?

$(100=$ Follow extremely closely $\ldots . .0=$ Do not follow at all)

\section{Medication benefit relevance}

Following is a list of benefits that Brand $\mathrm{X}$ could provide. Please rate how relevant each benefit is for you personally in your efforts to treat your diabetes. $(100=$ Extremely relevant, $75=$ Very relevant, $50=$ Somewhat relevant, $25=$ Not very relevant, $0=$ Not at all relevant)

- Avoiding high blood sugar after meals

- Avoiding low blood sugar

- Avoiding weight gain

- Avoiding discomfort and inconvenience

\section{Medication benefit rating}

If Insulin User: How do the following benefits of Brand X compare to other insulin treatments currently on the market? If not Insulin User: How do the following benefits of Brand X compare to the medicine you currently take to manage your diabetes? $(50=$ Much better than other insulin treatments, $25=$ Somewhat better than other insulin treatments, $0=$ About the same as other insulin treatments, $-25=$ Somewhat worse than other insulin treatments, $-50=$ Much worse than other insulin treatments) 
- Avoiding high blood sugar after meals

- Avoiding low blood sugar

- Avoiding weight gain

- Avoiding discomfort and inconvenience

\section{Comparison to current medication}

Overall, how would you compare Brand X to your current diabetes treatment plan? Brand $\mathbf{X}$ is.... ( $50=$ Much better than my current diabetes treatment, $25=$ Somewhat better than my current diabetes treatment, $0=$ About the same as my current diabetes treatment, $-25=$ Somewhat worse than my current diabetes treatment, $-50=$ Much worse than my current diabetes treatment).

\section{Interesting in using inhaled insulin}

Having read about Brand $\mathrm{X}$, how interested would you be in talking to your doctor about Brand $\mathrm{X}$ once it is available?
If you are not currently on insulin, please consider your interest in Brand $\mathrm{X}$ if insulin becomes a therapy you are considering with your doctor. (100 = Extremely Interested, $75=$ Very Interested, $50=$ Somewhat Interested, $25=$ Not Very Interested, $0=$ Not at All Interested).

\section{Impact of inhaled insulin on insulin initiation}

If your doctor said that you needed to start taking insulin, how would the availability of Brand X make you feel about starting? $(50=$ I would be much more willing to start, $25=$ I would be somewhat willing to start, $0=$ I would be neither more nor less willing to start, $-25=$ I would be somewhat less willing to start, $-50=$ I would be much less willing to start).

\section{Publish your work in this journal}

Patient Preference and Adherence is an international, peer-reviewed, open access journal focusing on the growing importance of patient preference and adherence throughout the therapeutic continuum. Patient satisfaction, acceptability, quality of life, compliance, persistence and their role in developing new therapeutic modalities and compounds to optimize clinical outcomes for existing disease states are major areas of interest. This journal has been accepted for indexing on PubMed Central. The manuscript management system is completely online and includes a very quick and fair peer-review system. Visit http://www.dovepress.com/ testimonials.php to read real quotes from published authors. 